\title{
ESTIMASI KECEPATAN GELOMBANG GESER BAWAH PERMUKAAN PADA LAPISAN DANGKAL MENGGUNAKAN DATA MIKROTREMOR DI DAERAH MAMBORO
}

\author{
THE VELOCITY ESTIMATION OF SUBSURFACE SHEAR-WAVE IN THE SHALLOW LAYERS \\ USING MICROTREMOR DATA INI MAMBORO AREA OF PALU CITY
}

\author{
Indra $^{1)}$, Rustan Efendi ${ }^{1}$, Abdullah ${ }^{1)}$ \\ ${ }^{1)}$ Program Studi Fisika Jurusan Fisika FMIPA, Universitas Tadulako, Palu, Indonesia
}

\begin{abstract}
ABSTRAK
Penelitian Estimasi Kecepatan Gelombang Geser Bawah Permukaan Pada Lapisan Dangkal telah dilakukan menggunakan data mikrotremor di Daerah Mamboro Kecamatan Palu Utara Kota Palu. Tujuan penelitian untuk menganalisis kecepatan penjalaran gelombang geser lapisan batuan hingga kedalaman $30 \mathrm{~m}$ dan mengetahui tipe dan profil jenis lapisan batuan Daerah Mamboro. Pengambilan data dilakukan pada lintasan yang berbeda yaitu lintasan-1 yang berada disekitar terminal Mamboro, lintasan-2 berada disekitar tempat penampungan ikan dan lintasan-3 berada di lapangan Sekolah Tinggi Ilmu Kesehatan Mamboro. Metode pengambilan data menggunakan Microtremor Array Measurements (MAM) dan metode pengolahan data menggunakan Multi Analysis of Surface Wave (MASW) dengan menggunakan software Surface Wave Analysis Wizard dan software WaveEq dari Geometris. Hasil penelitian menunjukkan bahwa ketiga lintasan tersebut tergolong dalam tipe batuan yang sama yaitu tipe D yang berjenis tanah sedang dengan nilai Vs30 berturut-turut sebesar $243,1 \mathrm{~m} / \mathrm{s}, 243,7 \mathrm{~m} / \mathrm{s}$ dan $231,1 \mathrm{~m} / \mathrm{s}$. Hasil dari hubungan kecepatan gelombang geser terhadap lintasan bawah permukaan pada daerah penelitian tersusun atas pasir tidak tersaturasi, alluvium dan lempung, sehingga daerah penelitian rentan terhadap kerusakan akibat gempa.
\end{abstract}

Kata Kunci: Gelombang geser, mikrotremor, jenis batuan.

\begin{abstract}
The research on Estimation of The Shear-Waves Velocity In Shallow-Subsurface Layers has been carried out using microtremor data in Mamboro Area, North Palu District, Palu City. The purpose of this study was to analyze the velocity of shear-wave propagation of rock layers to a depth of $30 \mathrm{~m}$ and determine the type and profile of the rock layers in the Mamboro Region. Data retrieval aasis carried out on different trajectories, namely track-1 which is around Mamboro Terminal, track-2 was in the vicinity of fish shelters and settlements and track-3 is in the field of the Mamboro School of Health Sciences. Data retrieval method uses Microtremor Array Measurements (MAM) and data processing methods using Multi Analysis of Surface Wave (MASW) using Surface Wave Analysis Wizard software and Geometric WaveEq software. The results showed that the three trajectories belong to the same rock type namely type $D$ which is medium type with Vs30 values of $243.1 \mathrm{~m} / \mathrm{s}, 243.7 \mathrm{~m} / \mathrm{s}$ and $231.1 \mathrm{~m} / \mathrm{s}$, respectively. The results of the relation Vs30 on the subsurface trajectory in the study area are composed of unsaturated sand, alluvium and clay. Thus the research area is vulnerable to damage due to earthquake shocks.
\end{abstract}

Keywords: Shear wave, microtremors, rock types.

\section{PENDAHULUAN}

Pembangunan merupakan suatu upaya yang dilakukan secara terus menerus untuk mendapatkan tingkat kehidupan masyarakat yang sejahtera. Kelurahan Mamboro merupakan salah satu kelurahan yang berada di Kota Palu yang perkembanganya sangat pesat. Perkembangan tersebut terlihat dari banyaknya pembangunan 
perkantoran, sekolah, dan juga pembangunan sarana dan prasarana kesehatan. Aktifitas pembangunan yang cukup tinggi membuat sebagian besar masyarakat kurang mempertimbangkan kondisi batuan bawah permukaan ketika melakukan pembangunan dengan kapasitas yang cukup besar yang didirikan, sehingga kerusakan bangunan tidak dapat dihindari ketika gempa terjadi.

Gempa merupakan salah satu penyebab kerusakan bangunan yang terjadi karena adanya pelepasan energi yang dihasilkan oleh tekanan yang dilakukan oleh lempengan yang bergerak. Banyak studi menunjukkan bahwa kerusakan infrastruktur akibat gempa bumi lebih besar terjadi pada wilayah yang tanahnya tidak terkonsolidasi dengan baik. Hal ini seharusnya menjadi pemikiran dalam pengembangan perencanaan pembangunan kedepan, misalnya untuk perencanaan pembangunan tahan gempa. Proses perencanaan bangunan tahan gempa sangat dipengaruhi oleh kondisi lapisan batuan serta lokasi yang menjadi pusat untuk mendirikan bangunan. Seperti diketahui bahwa getaran yang disebabkan oleh gempa cenderung membesar pada lapisan batuan lunak jika dibandingkan pada lapisan batuan keras ataupun padat. Tanah yang tidak terkonsolidasi dengan baik memiliki kontras densitas dan kecepatan gelombang geser (Vs) yang besar pada bagian bedrock, bagian atas perlapisan yang tidak terkonsolidasi memiliki nilai densitas dan Vs yang rendah dan bedrock yang keras memiliki nilai densitas dan Vs yang tinggi. Secara seismik, hal seperti ini biasanya menyebabkan tanah tersebut memiliki sifat amplifikasi yang besar terhadap getaran yang datang, seperti getaran gempabumi. Apabila terjadi gempa bumi, maka daerah dengan nilai amplifikasi yang besar mengalami getaran yang lebih kuat sehingga daerah tersebut dapat terkena dampak yang lebih parah (Indra, 2011).

Menurut Nurrahmi, dkk, (2015) Sebagaimana diketahui bahwa getaran yang disebabkan oleh gempa cenderung membesar pada batuan lunak dibandingkan pada batuan keras atau padat.
Penentuan pembesaran gelombang dapat ditentukan melalui klasfikasi jenis batuan berdasarkan data batuan pada kedalaman hingga $30 \mathrm{~m}$ dan lapisan-lapisan batuan sampai kedalaman $30 \mathrm{~m}$. Sebagaimana diungkapkan oleh Roser dan Gosar (2010), nilai Vs30 dapat dipergunakan dalam penentuan standar bangunan tahan gempa. Untuk mengetahui jenis batuan bawah permukaan dapat ditentukan dengan menggunakan metode geofisika.

Penerapan Vs30 lainnya telah dilakukan oleh Ariestianty dkk. (2010) analisis gelombang permukaan dengan menggunakan beberapa alat penerima (geofon) atau Multi Analysis of Surface Wave (MASW). MASW adalah salah satu pengujian seismik yang bersifat non destruktif untuk mengukur kecepatan gelombang geser (Vs30). Secara umum metode MASW mengukur variasi kecepatan gelombang permukaan seiring dengan bertambahnya kedalaman. Prinsip survey MASW didasarkan pada teori perambatan gelombang Rayleigh dimana gelombang tersebut dihasilkan dari interaksi gelombang geser dengan lapisan tanah permukaan. Dengan mengukur kecepatan rambat gelombang permukaan Rayleigh maka dapat diperkirakan profil Vs30 (Muzli, dkk, 2016).

Salah satu metode geofisika yang dapat mendeteksi kecepatan penjalaran gelombang geser hingga kedalaman $30 \mathrm{~m}$ (Vs30) adalah metode Microtremor Array Measurements (MAM). Metode ini merekam penjalaran gelombang geser yang menjalar di bawah permukaan dengan menggunakan sensor data dari sumber gelombang alami. Oleh karena itu, untuk mengetahui perlapisan jenis batuan bawah permukaan berdasarkan analisis pada gelombang geser di Daerah Mamboro, maka penelitian dilakukan dengan menggunakan metode MAM.

Berdasarkan Peta Geologi Tinjau Lembar Palu (Sukamto, 1973), Formasi batuan pada lokasi penelitian dan sekitarnya merupakan litologi aluvium dan endapan pantai yang terdiri dari 
kerikil, pasir, lumpur dan batu gamping koral yang ditunjukkan pada Gambar 1.

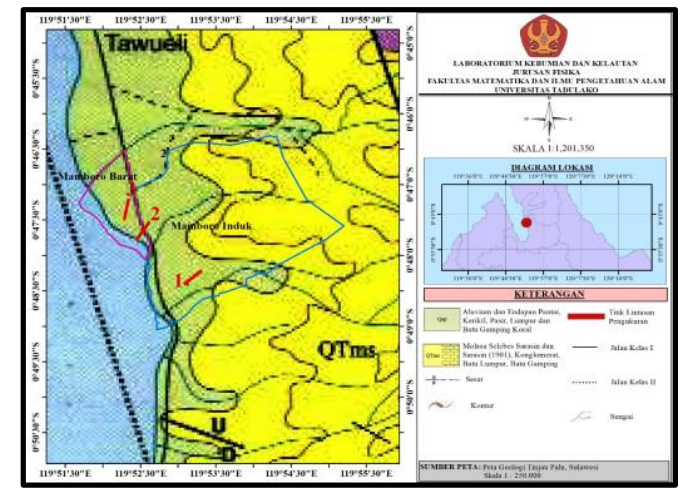

Gambar 1. Peta geologi lokasi penelitian

Gelombang seismik adalah gelombang yang menjalar di dalam bumi yang disebabkan adanya deformasi struktur, tekanan ataupun tarikan karena sifat keelastisan kerak bumi. Gelombanggelombang yang merambat baik di dalam maupun di permukaan bumi berasal dari sumber seismik seperti dari sumber gempa, ledakan (proses kimia dan nuklir), erupsi gunung api, dan longsoran. Gelombang ini membawa energi kemudian menjalarkan ke segala arah di seluruh bagian bumi dan mampu dicatat oleh seismograf. Perambatan gelombang seismik menembus struktur perlapisan bumi sangat bergantung pada sifat elastisitas batuan-batuan yang dilaluinya (Siswowidjoyo, 1997).

Kecepatan penjalaran gelombang seismik ditentukan oleh karakteristik lapisan dimana gelombang tersebut menjalar. Kecepatan gelombang seismik dipengaruhi oleh rigiditas (kekakuan) dan kerapatan lapisan sebagai medium bagi penjalaran gelombang, ini ditinjau dari segi lapisan yang dilalui. Perbedaan karakteristik lapisan dapat mengidentifikasi adanya variasi kecepatan gelombang seismik terhadap arah yang berbeda. Adanya perbedaan kecepatan gelombang terhadap arah dapat diakibatkan oleh beberapa faktor yaitu konfigurasi susunan mineral, rekahan dan pori-pori batuan (Uswatun, 2012).

Gelombang geser mendeformasi batuan dengan mengubah bentuk. Gelombang ini dapat merambat pada padatan saja, sehingga gelombang geser saja yang melaluinya dapat diteruskan ke pemukaan. Kecepatan perambatanya lebih rendah dari pada gelombang longitudinal atau gelombang primer, dan ketika terjadi gempa, gelombang ini akan tercatat setelah gelombang primer. Dasar inilah sehingga gelombang geser dinamakan gelombang sekunder. Gelombang geser merupakan gelombang tranversal, karena arah geraknya tegak lurus terhadap arah perambatannya (Susilawati, 2008). Sifat fisik batuan menjadi salah satu faktor yang mempengaruhi kecepatan rambat gelombang seismik. Setiap jenis batuan, seperti terlihat pada Tabel 1 baik batuan beku, batuan sedimen ataupun batuan vulkanik memiliki perbedaan dalam kemapuan sebagai medium perambatan gelombang seismik.

Tabel 1. Nilai kecepatan Gelombang Primer, Kecepatan Gelombang Sekunder dan Densitas Berdasarkan Jenis Material (Widodo. P., 2012)

\begin{tabular}{|c|c|c|c|c|}
\hline \multirow[b]{2}{*}{ No. } & \multirow[b]{2}{*}{ Material } & \multicolumn{2}{|c|}{ Kecepatan $(\mathrm{m} / \mathrm{s})$} & \multirow{2}{*}{$\begin{array}{c}\text { Densitas } \\
\left(\mathrm{g} / \mathrm{cm}^{3}\right)\end{array}$} \\
\hline & & $\begin{array}{c}\text { Gelombang } \\
\text { P }\end{array}$ & $\begin{array}{c}\text { Gelombang } \\
\mathrm{S}\end{array}$ & \\
\hline 1. & Udara & 330 & - & \\
\hline 2. & Air & $1400-1500$ & & 1000 \\
\hline 3. & Baja & 6100 & 3500 & \\
\hline 4. & Beton & 3600 & 2000 & $2350-2450$ \\
\hline 5. & $\begin{array}{c}\text { Granit } \\
\text { Dolerit } \\
\text { Gabro } \\
\text { Ryolit } \\
\text { Andesit } \\
\text { Basal }\end{array}$ & $\begin{array}{l}4500-6500 \\
3500-6700 \\
4500-7000 \\
4500-6500 \\
5000-7000\end{array}$ & $\begin{array}{l}3500-3800 \\
2960-3450 \\
2700-3500 \\
\\
2440-3500 \\
3600-3700\end{array}$ & $\begin{array}{l}2350-2620 \\
2800-3000 \\
2720-3000 \\
2400-2600 \\
2500-2800 \\
2210-2700\end{array}$ \\
\hline 6. & $\begin{array}{c}\text { Pasir (Tidak } \\
\text { Tersaturasi) } \\
\text { Pasir } \\
\text { (Tersaturasi) } \\
\text { Lempung } \\
\text { Aluvium }\end{array}$ & $\begin{array}{c}200-1000 \\
800-2000 \\
1000-2500 \\
1500-2500\end{array}$ & $\begin{array}{c}80-400 \\
320-8800 \\
400-1000 \\
120-3600\end{array}$ & $\begin{array}{l}2000-2600 \\
2500-2800\end{array}$ \\
\hline
\end{tabular}

Menurut Muzli dkk, 2016, Vs30 adalah indikator yang baik untuk menggambarkan karakteristik kekakuan dan kekuatan tanah. Meskipun demikian, pengukuran Vs30 secara langsung dengan kuantitas dan kualitas data yang baik dan biaya operasional yang ekonomis umumnya sulit dilakukan. Vs30 merupakan kecepatan gelombang geser yang dapat dideteksi pada kedalaman hingga $30 \mathrm{~m}$ dari permukaan. Nilai Vs30 ini dapat dipergunakan dalam penentuan standar bangunan tahan gempa. Umumnya kecepatan gelombang 
geser hingga kedalaman $30 \mathrm{~m}$ dari permukaan disebut dengan Vs30. Nilai Vs30 digunakan untuk menentukan klasifikasi batuan berdasarkan kekuatan getaran gempabumi akibat efek lokal serta digunakan untuk keperluan dalam perancangan bangunan tahan gempa. Vs30 merupakan data yang penting dan paling banyak digunakan dalam teknik geofisika untuk menentukan karakteristik struktur bawah permukaan hingga kedalaman 30 meter (Roser dan Gosar, 2010).

Ketika gelombang gempa menjalar dari batuan dasar ke atas permukaan maka gelombang akan mengalami amplifikasi. Besarnya amplifikasi ditentukan oleh jenis atau sifat fisik batuannya. Nilai kecepatan gelombang geser dari permukaan sampai kedalamn 30 meter (Vs30) digunakan sebagai standar besarnya amplifikasi. Menurut Wangsadinata, 2006, penelitian hanya pada lapisan-lapisan batuan sampai kedalaman $30 \mathrm{~m}$ yang dapat menetukan perbesaran gelombang. Nilai Vs30 dapat ditentukan dengan menggunakan Persamaan (1).

$$
V_{s} 30=\frac{\sum_{i=1}^{m} t_{i}}{\sum_{i=1}^{m} t_{i} / V_{s i}}
$$

Dengan $i$ adalah indeks pelapisan, $m$ adalah merupakan jumlah lapisan hingga kedalaman 30 meter, $t i$ adalah ketebalan lapisan ke- $i$ dan Vs30 adalah kecepatan gelombang geser hingga kedalaman 30 meter.

Pengetahuan tentang karakteristik atau sifat batuan sangat dibutuhkan untuk menganalisis sifat dinamis batuan, sehingga kekakuan batuan dan kuat geser batuan dapat diketahui, dengan mengukur kecepatan gelombang geser hingga kedalaman $30 \mathrm{~m}$. Klasifikasi jenis batuan berdasarkan pada kecepatan rambat rata-rata gelombang geser hingga kedalaman $30 \mathrm{~m}$ (Vs30) dapat dilihat pada Tabel 2.
Tabel 2. Klasifikasi jenis batuan berdasarkan nilai Vs30 sesuai dengan standar NHERP (FEMA 302. (1997)

\begin{tabular}{|c|c|c|}
\hline $\begin{array}{c}\text { Tipe } \\
\text { Batuan }\end{array}$ & Profil Jenis Batuan & Vs30 \\
\hline A & Hard Rock (Batuan Keras) & $>1.500 \mathrm{~m} / \mathrm{s}$ \\
\hline B & Rock (Batuan Sedang) & $760-1.500 \mathrm{~m} / \mathrm{s}$ \\
\hline C & $\begin{array}{c}\text { Very Dense Soil and Soft } \\
\text { Rock (Tanah Keras dan } \\
\text { Batuan Lunak) }\end{array}$ & $360-760 \mathrm{~m} / \mathrm{s}$ \\
\hline D & Stiff Soil (Tanah Sedang) & $180-360 \mathrm{~m} / \mathrm{s}$ \\
\hline E & Soft Soil (Tanah Lunak) & $<180 \mathrm{~m} / \mathrm{s}$ \\
\hline
\end{tabular}

Nilai Kecepatan gelombang geser bawah permukaan hingga kedalaman $30 \mathrm{~m}$ digunakan untuk klasifikasi batuan berdasarkan kekuatan getaran gempa bumi akibat efek lokal. Nilai Vs30 dapat dipergunakan untuk memperkirakan bahaya gempa bumi dan penentuan standar bangunan tahan gempa. Hal ini merupakan tahap dasar yang diperlukan untuk mengurangi resiko bencana gempa bumi, agar dapat menjadi salah satu tinjauan Pemerintah Daerah dalam mengatur tata ruang dan wilayah dalam pembangunan yang dilakukan kedepanya (Rosar dan Gosar, 2010).

\section{METODE PENELITIAN}

Penelitian dilakukan pada tanggal 5 mei 2018 di Daerag Mamboro yang termasuk dalam wilayah Kecematan Palu Utara Kota Palu. Posisi pengukuran berada pada ketinggian 8 meter sampai 36 meter di atas permukaan.

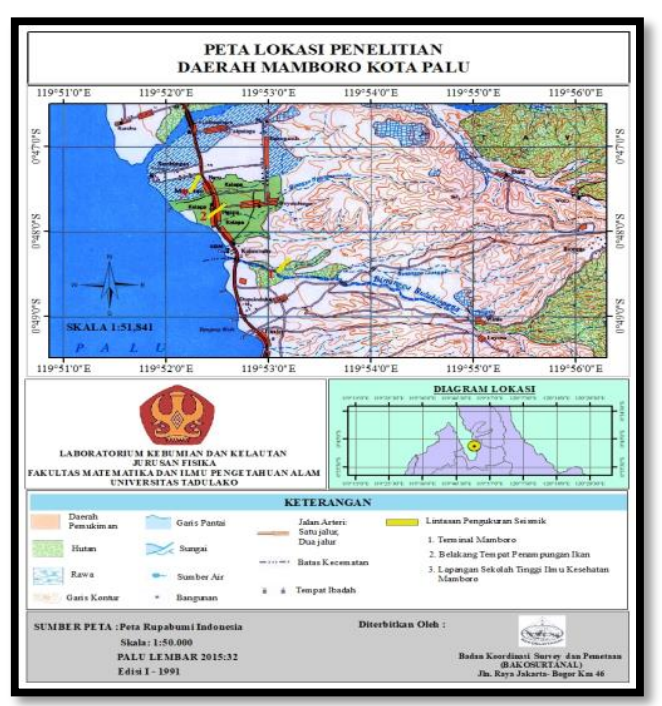

Gambar 2. Peta lokasi penelitian 
Dalam akuisisi data dilapangan menggunakan Seismik Geometris ES-3000 sebagai alat untuk merekam penjalaran gelombang. Kabel penghubung (trigger, extension, konector) berfungsi sebagai penghantar arus listrik. Detector Geophone 12 chanel sebagai sensor untuk mendeteksi perambatan gelombang dibawah permukaan. GPS berfungsi untuk menetukan posisi setiap geophone. Pengambilan data dilakukan menggunakan metode Microtremor Array Measurements (MAM) passive yaitu dengan menggunakan sumber gangguan alam sebagai sumber energi. Pada Pengukuran menggunakan jarak 4 meter untuk sertiap geophone sehingga total jarak dari satu lintasan adalah 44 meter. Pengukuran dilakukan sebanyak 3 lintasan di lokasi yang berbeda. Lintasan 1 dilakukan di sekitar Terminal Mamboro, lintasan 2 dilakukan di sekitar Tempat Penampungan Ikan Mamboro dan lintasan 3 dilakukan di lapangan Sekolah Tinggi Ilmu Kesehatan Mamboro.

Pengolahan data di lakukan untuk memperoleh penampang bawah permukaan pada lokasi penelitian. Data yang diperoleh kemudian diolah menggunakan Software Wave Analysis Wizard untuk mendapatkan kurva dispersi. Hasil kurva dispersi kemudian dilakukan inversi dengan menggunakan program WaveEq untuk mendapatkan profil kecepatan gelombang geser yang ditampilkan dalam bentuk 1 dimensi.

Interpretasi data dilakukan dengan menganalisis profil kecepatan gelombang geser untuk menentukan struktur batuan bawah permukaan hingga kedalaman $30 \mathrm{~m}$. Klasifikasi jenis batuan bawah permukaan dilakukan berdasarkan nilai kecepatan gelombang geser serta ketebalan setiap lapisan yang terbentuk hingga kedalaman $30 \mathrm{~m}$ dengan menggunakan Persamaan (1), dan mengacu pada Tabel (2).

\section{HASIL DAN PEMBAHASAN}

\section{Hasil Pengukuran Mikrotremor}

Hasil yang diperoleh dari proses pengambilan data adalah rekaman penjalaran gelombang geser pada lapisan bawah permukaan yang terekam pada seismograf. Gelombang yang terekam merupakan hubungan antara waktu yang dibutuhkan untuk merambat menuju lapisan batuan di bawah permukaan kemudian kembali memantul ke penerima gelombang di permukaan dan akan terekam melalui geophone seperti ditunjukkan pada Gambar 3 sampai Gambar 5. Gelombang yang terbentuk merupakan hubungan antara rekaman waktu dan jarak geophone untuk merambat menuju lapisan batuan bawah permukaan kemudian dipantulkan ke permukaan dan diterima oleh geophone.

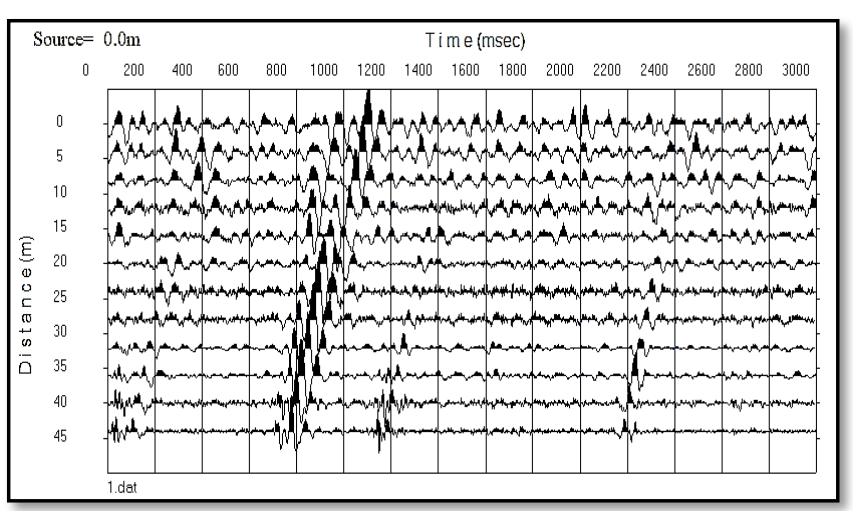

Gambar 3. Rekaman penjalaran gelombang geser menggunakan sumber pasif pada Lintasan-1

Lokasi pengukuran Lintasan-1 berada di Kelurahan Mamboro Induk disekitar Terminal Mamboro, RW 01/RT 03 dengan posisi pengukuran terletak pada koordinat $0^{\circ} 48^{\prime} 23,5^{\prime \prime}$ -

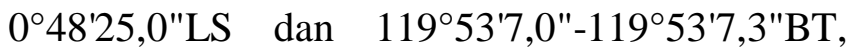
dibentangkan dengan arah lintasan $343^{\circ}$ arah Utara

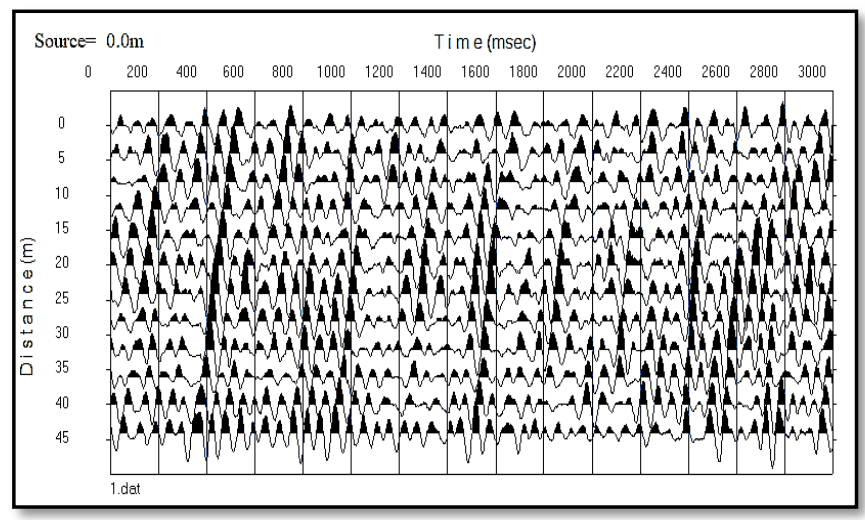

Gambar 4. Rekaman penjalaran gelombang geser menggunakan sumber pasif pada Lintasan-2

Lintasan-2 yang berada di wilayah Kelurahan Mamboro Barat RW 02/RT 01 disekitar tempat penampungan ikan dan pemukiman dengan posisi pengukuran terletak pada koordinat $0^{\circ} 47^{\prime} 46,6^{\prime \prime}$ - 
$0^{\circ} 47^{\prime}, 47,9^{\prime \prime}$ LS dan 11952'27,6"- 11952'27,8"

BT. Lintasan ini dibentangkan dengan arah lintasan $342^{\circ}$ arah Utara, dengan kondisi topografi cenderung datar yang memiliki elevasi $\pm 8 \mathrm{~m}$ dpl sampai $12 \mathrm{~m}$ dpl.

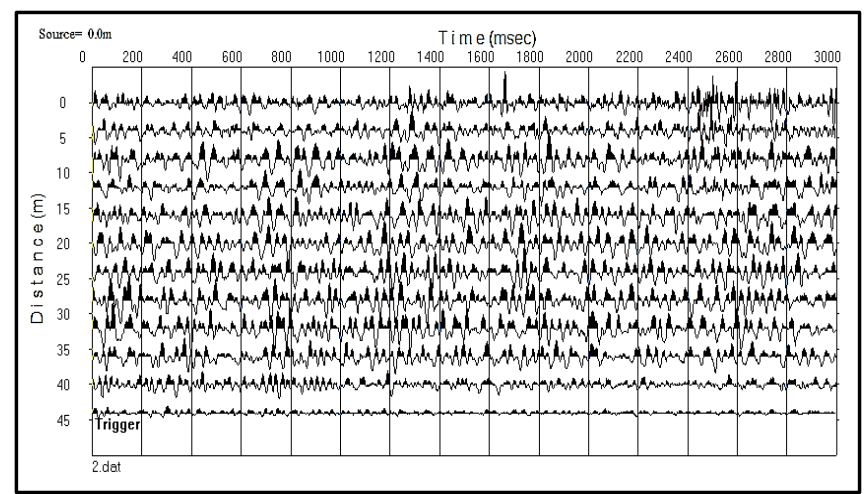

Gambar 5. Rekaman penjalaran gelombang geser menggunakan sumber pasif pada Lintasan-3

Gambar 5 merupakan rekaman penjalaran gelombang geser pada Lintasan-3 yang berada pada koordinat $0^{\circ} 47^{\prime} 28,1^{\prime \prime}-0^{\circ} 47^{\prime} 29,6^{\prime \prime}$ LS dan $119^{\circ} 52^{\prime} 17,1^{\prime \prime}-119^{\circ} 52^{\prime} 17,4^{\prime \prime}$ BT. Lintasan ini dibentangkan dengan arah lintasan $18^{\circ}$ arah utara, dengan kondisi topografi cenderung datar dengan elevasi $\pm 18 \mathrm{~m}$ dpl sampai $21 \mathrm{~m}$ dpl. Lokasi pengukuran berada di Lapangan Sekolah Tinggi Ilmu Kesehatan Mamboro yang berada di Kelurahan Mamboro Barat RW 03/RT 02 yang cenderung mendatar serta ditumbuhi oleh rumput.

\section{Hasil Pengolahan Data}

Data yang terekam dalam domain waktu dan jarak akan diubah ke domain frekuensi terhadap kecepatan fase menggunakan tranformasi Fourier. Hal tersebut dilakukan untuk mendapatkan kurva dispersi. Dispersi gelombang terjadi jika penjalaran gelombang memiliki kecepatan yang berbeda pada saat melalui lapisan batuan atau material di bawah permukaan. Hasil dari kurva dispersi menggunakan software Surface Wave Analisys Wizard, dari hasil tersebut memberikan informasi tentang kecepatan fase yang semakin meningkat secara linier terhadap frekuensi seperti ditunjukkan pada Gambar 6, Gambar 7 dan Gambar 8 sebagai berikut:

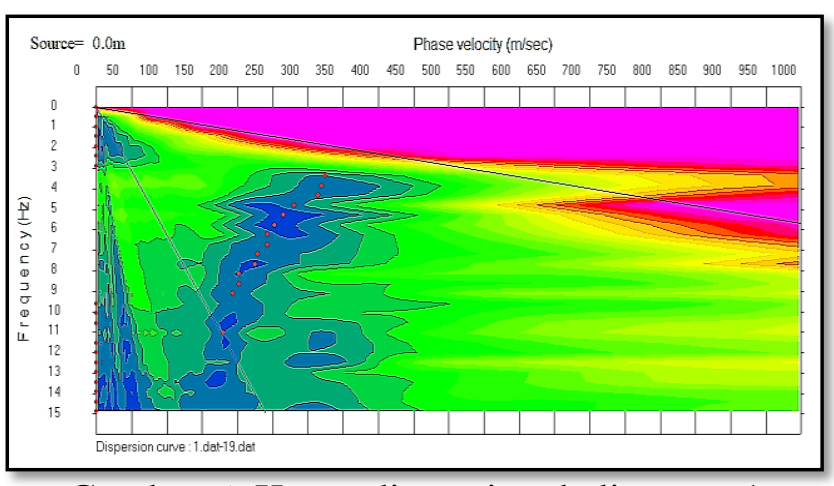

Gambar 6. Kurva dispersi pada lintasan-1

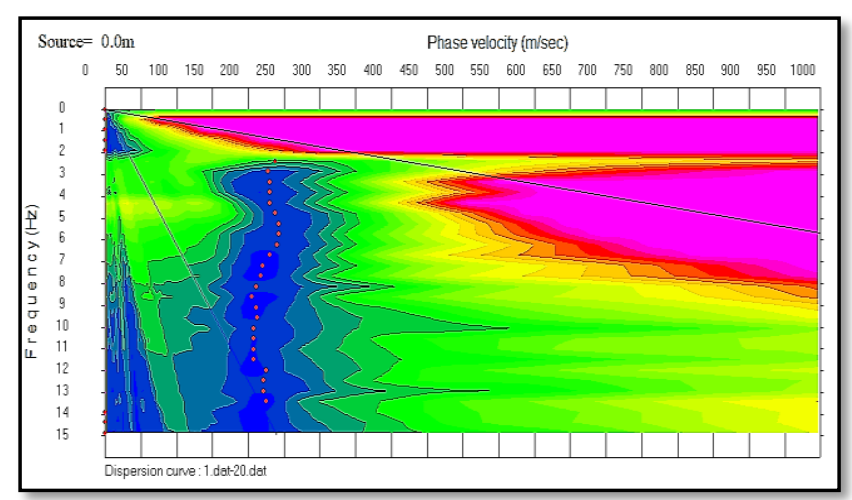

Gambar 7. Kurva dispersi pada Lintasan-2

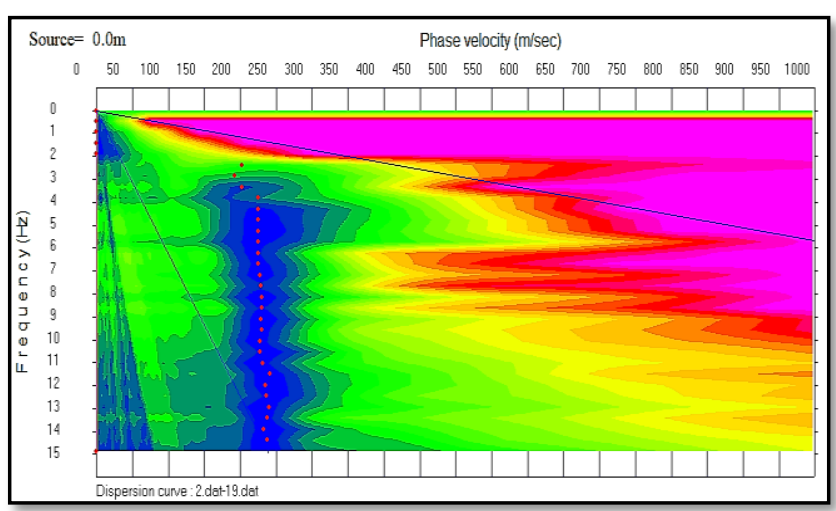

Gambar 8. Kurva dispersi pada Lintasan-3

Selanjutnya dari hasil kurva dispersi dilakukan inversi untuk medapatkan profil kecepatan gelombang geser lapisan batuan. Proses inversi dilakukan dengan menggunakan softwareWaveEq dari geometris. Proses inversi membutuhkan parameter awal yaitu ketebalan lapisan, sehingga dari parameter ini akan menjadi nilai awal dari iterasi yang telah dilakukan. Tingkat keakuratan dari inversi dapat dilihat dari RMSE (Root Mean Square Error), jika nilai error kurang dari 5\% yang dihasilkan maka hasil yang diperoleh dapat dikatakan terbebas dari noise dan proses inversi dapat dilanjutkan untuk mendapatkan profil kecepatan gelombang geser lapisan batuan. Nilai 
error yang diperoleh dari setiap lintasan kurang dari 5\% yaitu Lintasan-1 sebesar 3,6\%, Lintasan-2 sebesar $0,4 \%$ dan Lintasan-3 sebesar 3,8\%, sehingga hasil yang diperoleh dapat dilihat pada Gambar 9, Gambar 10 dan Gambar 11.

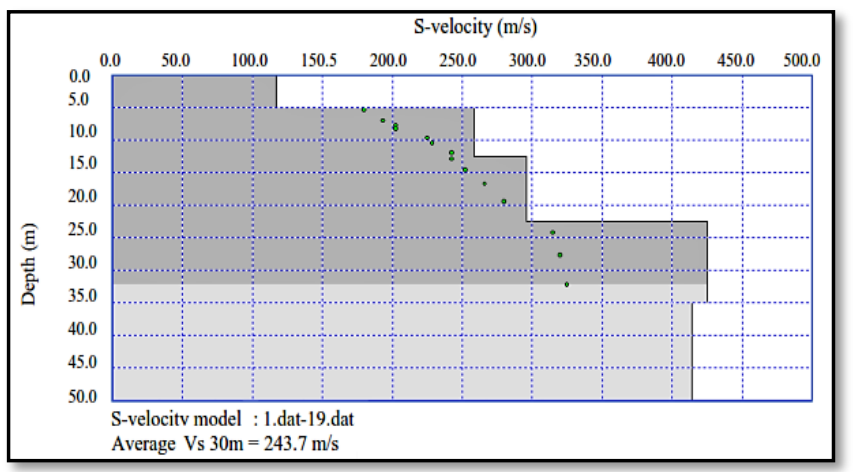

Gambar 9. Profil kecepatan gelombang geser pada Lintasan-1

Gambar 9 merupakan hasil pemodelan 1-D MASW analysis Lintasan-1 yang menujukkan kedalaman $50 \mathrm{~m}$ dan memiliki 5 lapisan batuan. Pada gambar tersebut menunjukkan pula total ketebalan yang terdeteksi mencapai 32,5 m dari muka tanah. Pada lapisan pertama memiliki ketebalan $\mathrm{h}=5 \mathrm{~m}$ dengan kecepatan rata-rata gelombang geser $\mathrm{Vs}=117 \mathrm{~m} / \mathrm{s}$ yang di dominasi oleh pasir tidak terasturasi. Lapisan kedua memiliki $\mathrm{h}=7,5 \mathrm{~m}$ dan $\mathrm{Vs}=257 \mathrm{~m} / \mathrm{s}$ yang diduga merupakan batuan Aluvium. Lapisan ketiga memiliki $\mathrm{h}=10 \mathrm{~m}$ dengan $\mathrm{Vs}=293 \mathrm{~m} / \mathrm{s}$ di duga merupakan batuan alluvium pula. Lapisan keempat memiliki $\mathrm{h}=35 \mathrm{~m}$ dan $\mathrm{Vs}=436 \mathrm{~m} / \mathrm{s}$ yang didominasi oleh lempung, sedangkan lapisan kelima di duga merupakan batuan alluvium dengan ketebalan $15 \mathrm{~m}$ dengan $\mathrm{Vs}=408 \mathrm{~m} / \mathrm{s}$ seperti yang terlihat pada Tabel 2. Berdasarkan hasil perhitungan nilai kecepatan pada kedalaman $30 \mathrm{~m}$ (Vs30) di peroleh sebesar 243,7 m/s.

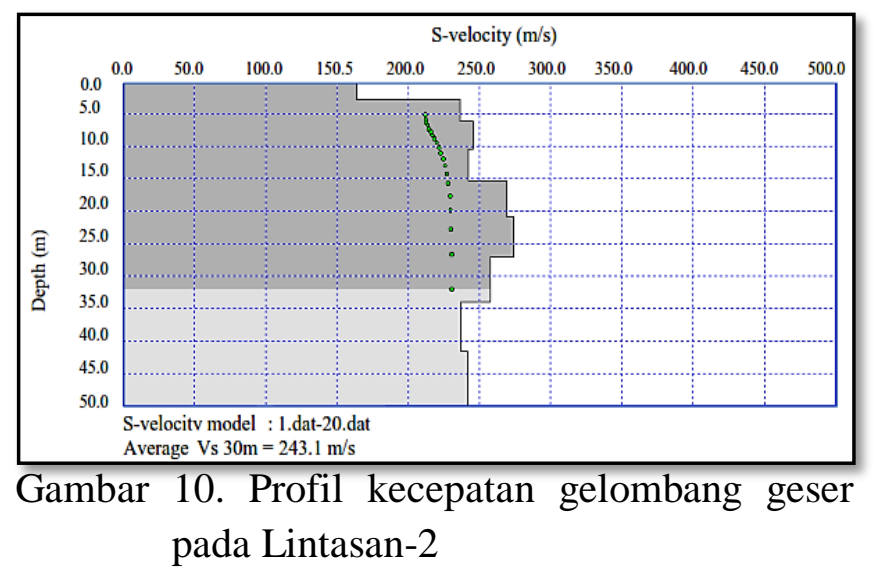

Gambar 10 adalah hasil model profil 1-D lintasan 2 yang telah di interpretasikan dan memiliki 9 lapisan dengan total ketebalan lapisan yang terdeteksi mencapai $32 \mathrm{~m}$. Pada lintasan ini memiliki range harga kecepatan gelombang yang hampir sama sehingga didominasi oleh jenis batuan yang sama yaitu batuan alluvium, seperti yang terlihat pada Tabel 4.1. dan nilai Vs30 di peroleh sebesar $243,1 \mathrm{~m} / \mathrm{s}$.

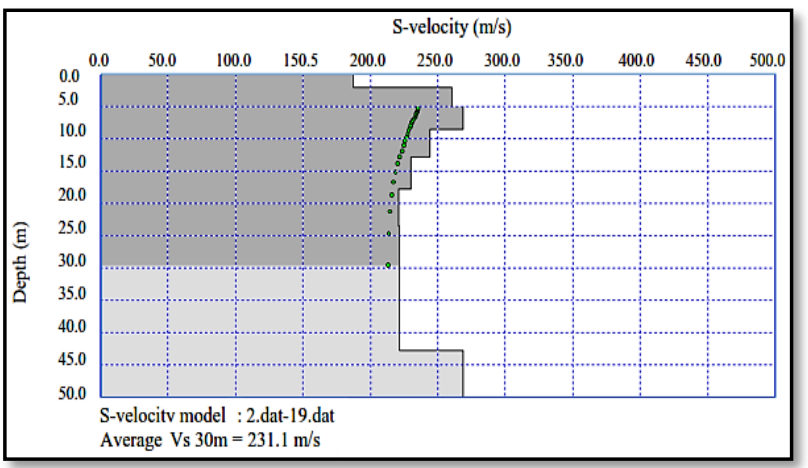

Gambar 4.9 Profil kecepatan gelombang geser pada Lintasan-3

Berdasarkan Gambar 4.9 terlihat bahwa Lintasan3 dengan model profil 1-D memiliki 8 lapisan dengan total ketebalan yang terdeteksi mencapai $30 \mathrm{~m}$ dan nilai Vs30 di peroleh sebesar $23,1 \mathrm{~m} / \mathrm{s}$. Dari profil kecepatan gelombang geser pada lintasan 3 telihat ketebalan dan kedalaman yang memiliki variasi nilai kecepatan gelombang geser tidak jauh berbeda antara nilai kecepatan gelombang geser lapisan ke 1 sampai lapisan ke 8, sehingga berdasarkan hasil interpretasi pada Tabel 1 pada lintasan ini di dominasi oleh batuan alluvium. Nilai Kecepatan gelombang geser terhadap kedalaman pada setiap lapisan dapat dilihat pada Tabel 3. 
Tabel 3. Nilai gelombang geser terhadap kedalaman untuk Lintasan-1 sampai Lintasan-3

\begin{tabular}{|c|c|c|c|c|c|c|}
\hline & Lapisan & $\mathrm{d}(\mathrm{m})$ & $\mathrm{t}_{\mathrm{i}}(\mathrm{m})$ & $\begin{array}{c}\mathrm{Vs} \\
(\mathrm{m} / \mathrm{s})\end{array}$ & $\begin{array}{c}\text { Jenis } \\
\text { Batuan }\end{array}$ & $\begin{array}{l}\text { Vs30 } \\
(\mathrm{m} / \mathrm{s})\end{array}$ \\
\hline \multirow{5}{*}{ 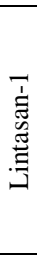 } & 1 & $0-5$ & 5 & 117 & $\begin{array}{c}\text { Pasir tidak } \\
\text { tersturasi }\end{array}$ & \multirow{5}{*}{243,7} \\
\hline & 2 & $5-12,5$ & 7,5 & 258 & \multirow{2}{*}{ Alluvium } & \\
\hline & 3 & $12.5-22,5$ & 10 & 296 & & \\
\hline & 4 & $22,5-35$ & 7,5 & 425 & Lempung & \\
\hline & 5 & $35-50$ & 15 & 414 & Alluvium & \\
\hline \multirow{9}{*}{ 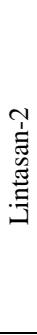 } & 1 & $0-2,7$ & 2,8 & 164 & \multirow{9}{*}{ Alluvium } & \multirow{9}{*}{243,1} \\
\hline & 2 & $2,8-6,3$ & 3,5 & 237 & & \\
\hline & 3 & $6,3-10,4$ & 4,2 & 245 & & \\
\hline & 4 & $10.4-15.3$ & 4,9 & 242 & & \\
\hline & 5 & $15,3-20,8$ & 5,6 & 270 & & \\
\hline & 6 & $\begin{array}{c}20,8- \\
27,1\end{array}$ & 6,3 & 274 & & \\
\hline & 7 & $27,1-34$ & 2,9 & 258 & & \\
\hline & 8 & $34-41,7$ & 7,7 & 237 & & \\
\hline & 9 & $41,7-50$ & 8,3 & 241 & & \\
\hline \multirow{8}{*}{ 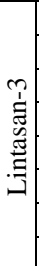 } & 1 & $0-2,1$ & 2,1 & 187 & \multirow{8}{*}{ Alluvium } & \multirow{8}{*}{231,1} \\
\hline & 2 & $2,1-5$ & 2,9 & 260 & & \\
\hline & 3 & $5-8,6$ & 3,6 & 269 & & \\
\hline & 4 & $8,6-12,9$ & 4,3 & 244 & & \\
\hline & 5 & $12,9-17,9$ & 5,0 & 230 & & \\
\hline & 6 & $17,9-23,6$ & 5,7 & 221 & & \\
\hline & 7 & $23,6-42,6$ & 19 & 222 & & \\
\hline & 8 & $42,6-50$ & 7,4 & 229 & & \\
\hline
\end{tabular}

Hasil pengolahan data yang diperoleh dapat diinterpretasikan hubungan antara lapisan batuan bawah permukaan berdasarkan analisis nilai kecepatan penjalaran gelombang geser yang berada di Daerah Mamboro Kota Palu. Pada lintasan-1 berada di belakang Terminal Mamboro, diperoleh nilai Vs30 sebesar $243,7 \mathrm{~m} / \mathrm{s}$ yang merupakan hasil dari perhitungan dengan menggunakan Persamaan 1. Sehingga berdasarkan Tabel 2. batuan yang berada di belakang Terminal Mamboro ini diklasifikasikan kedalam jenis batuan tipe D yang termasuk jenis tanah sedang. Pada Gambar 4.6 dapat dilihat bahwa pada kedalaman $30 \mathrm{~m}$, kecepatan gelombang pada lintasan-1 memiliki nilai yang berbeda-beda serta kedalaman dan ketebalan yang berbeda-beda yang terdiri dari 4 lapisan. Untuk kecepatan gelombang terkecil berada pada lapisan pertama dengan kedalaman 0-5 m dengan nilai Vs sebesar $117 \mathrm{~m} / \mathrm{s}$, sedangkan kecepatan gelombang terbesar berada pada lapisan keempat dengan kedalaman 22,5-30 $\mathrm{m}$ dengan nilai $\mathrm{Vs}$ sebesar $425 \mathrm{~m} / \mathrm{s}$ yang menunjukkan lapisan ini lebih keras daripada lapisan atasnya. Sehingga dapat diketahui bahwa semakin besar nilai Vs yang diperoleh maka batuan yang terdapat pada akan semakin keras.
Berdasarkan nilai kecepatan penjalaran gelombang geser pada Tabel 1. dapat dilihat bahwa untuk lapisan pertama ditafsirkan sebagai pasir tidak tersaturasi, lapisan kedua dan ketiga ditafsirkan sebagai endapan alluvium, sedangkan untuk lapisan keempat ditafsirkan sebagai lempung.

Untuk lintasan-2 terdapat di belakang Tempat Penampungan Ikan. Dari Gambar 4.7 dapat diketahui bahwa pada kedalaman $30 \mathrm{~m}$ terdapat kecepatan gelombang dengan nilai yang berbedabeda serta kedalaman dan ketebalan berbeda-beda yang terdiri dari 7 lapisan. Pada Tabel 2. dapat dilihat bahwa semakin besar kedalaman dan ketebalan yang diperoleh maka akan semakin besar pula nilai kecepatan gelombang. Pada lintasan ini untuk nilai kecepatan gelombang terkecil berada di lapisan pertama pada kedalaman 0-2,7 m dengan Vs sebesar $164 \mathrm{~m} / \mathrm{s}$ sedangkan untuk nilai kecepatan gelombang terbesar berada di lapisan keenam pada kedalaman 20.8-27.1 m dengan Vs sebesar $274 \mathrm{~m} / \mathrm{s}$. Hal ini menunjukkan bahwa semakin besar kedalaman maka batuanya akan semakin keras, namun masih berada pada jenis batuan yang sama. Sehingga berdasarkan hasil interpretasi yang diperoleh dari Tabel 1. dapat dilihat bahwa lapisan satu sampai tujuh memiliki jenis batuan yang sama ditafsirkan sebagai endapan alluvium. Sedangkan untuk nilai kecepatan kecepatan gelombang geser hingga kedalaman $30 \mathrm{~m}$ (Vs30) diperoleh nilai 243,1 m/s. Dengan demikian daerah di belakang tempat penampungan ikan ini diklafikasikan kedalam jenis batuan tipe D yaitu termasuk kedalam jenis tanah sedang.

Pada lintasan-3 terdapat di Lapangan Sekolah Tinggi Ilmu Kesehatan (STIKES) Mamboro, berdasarkan Gambar 11. dapat ketahui bahwa pada kedalaman $30 \mathrm{~m}$, kecepatan gelombang serta kedalaman dan ketebalan yang terdiri dari 7 lapisan dan diperoleh nilai yang berbeda-beda, dimana semakin besar kedalaman yang diperoleh maka akan semakin besar nilai kecepatan gelombangnya. Kecepatan gelombang terkecil dengan nilai Vs sebesar $187 \mathrm{~m} / \mathrm{s}$ berada dekat 
permukaan yaitu pada kedalaman 0-2,1 m sedangkan untuk kecepatan gelombang terbesar berada pada kedalaman 5-8.6 dengan nilai Vs sebesar $269 \mathrm{~m} / \mathrm{s}$. Sehingga berdasarkan hasil interpretasi, Nilai kecepatan gelombang geser yang diperoleh untuk lapisan pertama sampai lapisan kedelapan dapat ditafsirkan sebagai endapan alluvium. Nilai kecepatan gelombang geser hingga kedalam $30 \mathrm{~m}$ diperoleh sebesar $231,1 \mathrm{~m} / \mathrm{s}$. Pada lintasan ini nilai Vs30 yang dihasilkan tergolong rendah sehingga di Daerah STIKES Mamboro diklafikasikan kedalam jenis batuan tipe D yaitu termasuk kedalam jenis tanah sedang.

Sehingga berdasarkan analisis nilai kecepatan gelombang geser yang didapatkan dari 3 lintasan pengukuran tersebut masih tergolong rendah. Hal ini di karenakan daerah penelitian berada dalam 1 jenis tanah yang sama dengan tipe batuan yang sama pula yaitu jenis tanah sedang yang diklafikasikan kedalam jenis batuan tipe D. Namun dari setiap lintasan pengukuran terdapat perbedaan variasi pada nilai kecepatan gelombang geser. Hal ini terjadi karena karakteristik kecepataan rambat gelombang geser bergatung pada material penyusun di bawah permukaan. Hal tersebut menunjukkan bahwa semakin besar nilai kecepatan gelombang geser yang terjadi di bawah pemukaan maka semakin kompak jenis batuan penyusunannya.

Hasil dari hubungan nilai kecepatan gelombang geser terhadap lintasan bawah permukaan pada daerah penelitian tersusun atas endapan alluvium, pasir tidak tersaturasi dan lempung, sehingga daerah penelitian bisa dikatakan daerah yang rentan terhadap kerusakan akibat guncangan gempa. Sebagaimana diketahui bahwa getaran yang disebabkan oleh gempa cenderung membesar pada tanah lunak dan sedang dibandingkan pada tanah keras. Tanah lunak dan sedang akan memberikan respon getaran yang lebih tinggi ketika gempa bumi terjadi. Tanah lunak dan sedang akan menimbulkan amplifikasi terhadap getaran yang terjadi, sehingga mudah mengalami kerusakan ketika gempa terjadi. Selanjutnya, untuk kepentingan geoteknik dalam pendirian gedung, lapisan tanah sedang perlu dilakukan rekayasa geoteknik. Rekayasa dilakukan untuk memperkeras batuan agar dapat digunakan sebagai dasar bangunan. Memperkeras batuan dapat dilakukan dengan cara memadatkan lapisan tanah tersebut dan dapat pula dicampuri dengan batu gamping.

\section{KESIMPULAN}

Berdasarkan interpretasi serta hasil pengolahan data pada estimasi kecepatan gelombang geser di Daerah Mamboro Kota Palu dapat disimpulkan Berdasarkan analisis nilai kecepatan gelombang geser hingga kedalaman $30 \mathrm{~m}$ diiduga di dominasi oleh alluvium dengan kecepatan gelombang geser hingga kedalaman $30 \mathrm{~m}$ (Vs30) pada Lintasan-1 diperoleh 4 lapisan dengan nilai Vs30 yaitu 243,7 $\mathrm{m} / \mathrm{s}$, pada Lintasan-2 diperoleh 7 lapisan dengan nilai Vs30 yaitu 243,1 sedangkan pada Lintasan-3 diperoleh 7 lapisan dengan nilai Vs30 yaitu 231,1 $\mathrm{m} / \mathrm{s}$. Hasil penelitian ini menunjukkan bahwa estimasi struktur lapisan bawah permukaan menggunakan analisis gelombang geser menunjukkan bahwa pada lokasi penelitian pada Lintasan-1, Lintasan-2, dan Lintasan-3 diklasifikasikan memiliki tipe dan jenis tanah yang sama yaitu tipe D yaitu termasuk jenis tanah sedang.

\section{DAFTAR PUSTAKA}

[BMKG] Badan Metereologi, Klimatologi, dan Geofisika (2011). Tataan Tektonik Dan Sejarah Kegempaan Palu, Sulawesi Tengah bulan Januari 2011. Diperoleh dari website Badan Metereologi, Klimatologi, dan Geofisika: http://www.facebook.com/?ref=home\#!/pr ofile.php?id=1188787163. Diakses 4 April 2018.

[BPS] Badan Pusat Statistik (2017). Daftar Kabupaten dan Kota di Sulawesi Tengah Menurut Jumlah Penduduk. Diperoleh dari website Badan Pusat Statistik: https://palukota.bps.go.id/statictable/2017/ 06/13/599/jumlah-penduduk menurutkabupaten-kota-di-provinsi-sulawesi- 
tengah-ribu-2012-2016.html. Diakses 9 April 2018.

FEMA 302. (1997). NEHRP Recomended Provisions for Seismic Regulations for New Buildings and Other Structures. Washington, D. C: National Instituteof Building Sciences.

Indra, 2011. Penggunaan Dual Pass Diferential Deformasi (Studi Kasus: Sesar Palu Koro). ITB, Jawa Barat, Bandung.

Muzli, M., Mahesworo, R.P., Madijono, R., Siswoyo, Pramono, S., Dewi, R.K., Budiarto, Satiya, O., Sulistyo, B., Swastikarani, R., Oktavia, N., Moehajirin, Efendi, N., Wijaya, AT., Subadyo, B., Mujianto dan Suwarto, (2016). Pengukuran Vs30 Menggunakan Metode MASW untuk Wilayah Yogyakarta. BMKG, Vol. 17 No. 1, pp. 25-32.

Nurrahmi, Efendi, R., Sandra. (2015). Analisis Kecepatan Gelombang Geser Vs30 Menggunakan Metodrefraksi Mikrotremor (Remi) di Kelurahan Talise, Gravitasi. 14 (Hal 7-12). Palu: Jurusan Fisika FMIPA Universitas Tadulako.

Roser, J., and Gosar, A. (2010). Determination of Vs30 for Seismic Ground Classification in the Ljubljana area, Slovenia, Acta Geotechnica Slovenia

Siswowidjoyo, S., Sudarsono F.U., dan Wirakusumah, A.D., (1997). The Threat of Hazards in the Semeru Volcano Region in East Java, Indonesia. Journal of Asian Earth Sciences, Vol.15 Nos 2 -3, pp. 185 194.

Sukamto, R., (1973). Peta Geologi Lembar Palu, Sulawesi, Skala 1:250.000. Pusat Penelitian dan Pengembangan Geologi. Bandung

Susilawati. 2008. Penerapan Penjalaran Gelombang Seismik Gempa pada Penelaahan Struktur Bagian dalam Bumi. Universitas Sumatera Utara. Sumatera Utara.

Uswatun, C., (2012). Studi awal tentang model kecepatan gelombang $\mathrm{P}$ dan gelombang $\mathrm{S}$ untuk Mengetahui Struktur geologi, Alogaritma Genetika. Makalah Tugas
Akhir Simulasi Sistem Fisis. II UNESA Surabaya.

Wangsadinata, W. (2006).Perencanaan Bangunan Tahan Gempa Berdasarkan SNI 17262002. Shortcourse HAKI 2006. Jakarta.

Widodo, P., (2012). Seismologi Teknik \& Rekayasa Kegempaan, Universitas Islam, Yogyakarta. 